\title{
Interactive Digital Model of Assessing Energy Efficiency of Buildings
}

\author{
Omar Shakshak \\ Department of Information Technology \\ Saint Petersburg State University of \\ Architecture and Civil Engineering \\ Saint Petersburg, Russia \\ omar.shakshak@mail.ru*
}

Igor Yamshanov

Department of Civil Engineering and

Applied Ecology Institute of Civil

Engineering

Peter the Great St.Petersburg

Polytechnic University (SPdPU)

St.Petersburg, Russia

dartigor@mail.ru

\author{
Igor Evsikov \\ Department of Information Technology \\ Saint Petersburg State University of \\ Architecture and Civil Engineering \\ Saint Petersburg, Russia \\ ievsikov@lan.spbgasu.ru
}

\author{
Timur Ablyazov \\ Department of Construction Economics \\ and Housing and Utility Infrastructure \\ Saint Petersburg State University of \\ Architecture and Civil Engineering \\ Saint Petersburg, Russia \\ 3234969@mail.ru
}

\begin{abstract}
The issues of enhancement of energy efficiency of buildings acquire the ever-greater significance in the recent decades, since a demand for utilization of alternative energy sources and reduction of energy consumption as a whole increases with acceleration of urbanization process and depletion of reserves of natural energy resources. This article gives consideration to the basic methods of digital modeling of energy efficiency of buildings and offers an interactive digital model for assessing energy efficiency developed on the basis of joint use of virtual reality means and BIM model of construction object. The digital model performs heat-balance calculations, finds a necessary quantity of energy for heating as well as calculates efficiency of utilization of alternative energy sources such as solar cell panels and wind turbines. The user of this model is granted a chance of independent selection of average temperature in the future object that is especially important for residential buildings. At that, it is not necessary for the user to possess any special knowledge owing to a simple and intuitive interface. Working with the digital model a user has a chance to freely move, perform manipulations with the specified set of energy sources as well as interact with light sources and change the interior by means of virtual reality capabilities in real-time mode.
\end{abstract}

Keywords-BIM, energy efficiency of a building, digital model, VR, VDC, Unreal Engine, rendering in real-time mode

\section{INTRODUCTION}

Based on expert estimates the world population will grow up to $10 \mathrm{bln}$. people by 2050 , in this case $2.5 \mathrm{bln}$. people will live in the cities [1]. The accelerating urbanization leads to that it will be necessary to construct 13,000 buildings a day globally in the coming years [2]. A suchlike growth of cities will bring about the emergence of problems of efficiency of natural resources utilization: presently $40 \%$ of the world energy consumption account for residential buildings [1].

The up-to-date software in the field of informational modeling of buildings and structures makes it possible not only to assess the energy use during operation and construction and offer the most optimal materials and structures from the point of view of energy efficiency, but makes a basis for improving the interactive digital models to make the facilities management more efficient.

An issue of using alternative energy sources calls in special attention and, since the readily available reserves of natural gas will be sufficient in Russia for 50 years only [3]. The life cycle of the construction facility is averagely about 100 years; therefore, it is necessary to plan energy consumption for the long run too. The BIM technologies are used at all stages of the facility life cycle; the practice of using thereof outspreads even during renovation of residential blocks, however, the analysis of energy efficiency is not the main purpose of informational modeling [4]. The issues of energy efficiency of buildings are most frequently settled on the basis of specialized software; however, the potentialities of combination thereof with virtual reality capabilities have been studied insufficiently. So far, there is no convenient and high-quality software product, which will help to show distribution of warm and cold air flows in threedimensional space.

Presently, they begin to actively use the game engines for visualization of future construction facilities. This measure solves many problems in the construction sphere connected to presentation of future facilities, selling thereof as well as enhancement of energy performance of residential construction. The advantage of virtual presentation of construction facilities is an absolutely new stage in designing, construction and operation of houses and residential blocks. The use of virtual reality capabilities provides benefits in the marketing activity too: a potential buyer may not only see the final result of construction, virtually pass through its future place of residence and assess the advantages of selected facility, but also change some parameters, e.g., interior appearance, in real-time mode.

The distribution of heat in premises can be shown in the form of multicolor particles featuring blue color in cold areas

*corresponding author

The article was prepared as part of the work on the grant of the President of the Russian Federation NSh-4028.2018.6 
and red in warm areas using the special means of Unreal Engine game engine. This work gives a description of process of implementation of console-based application with an interactive digital model demonstrating a process of heat transfer on the basis of using virtual reality capabilities (VR) and BIM-technologies. In order to develop the mathematic model of heat transfer, it is necessary to analyze differential equations for revealing the most efficient solution. The informational model of building (BIM) created in the software complex Autodesk Revit has been taken as an experimental model for this research. The building design with three different heating systems is being built in this model. In future this project will be used in the Unreal Engine.

The interactive digital model helps the user freely move in 3D space, observe heat distribution and manipulate a specified set of heating systems as well as change some elements of the interior appearance in the real-time mode. This model helps determine an optimal quantity of energy sources taking into account the cost thereof and average annual energy generation. This model is also used to calculate efficiency of using alternative energy sources such as solar cell panels and wind turbines. Such an approach stimulates the users to changer over to energy-efficient systems, which is especially relevant in the framework of Energy strategy 2035 [5].

\section{LITERATURE REVIEW}

The significant benefits of using the building informational modeling (BIM), technologies of virtual designing and construction (VDC) have been acknowledged in scientific society [6]. The scholars have noted that such an approach helps to reveal errors of designing at the early stages, which considerably reduces a probability of subsequent corrections at the construction stage. The use of virtual reality technologies makes it possible to perform an efficient exchange of visual information between all participants of the construction project, which reduces time required for visual presentation of complex architectural and technical solutions, extends capabilities of marketing activity and resultantly improves the business reputation of the participants of designing and construction and leads to the buildup of business cooperation in the context of other projects.

Speaking about the analysis of building energy efficiency on the basis of BIM model, the remarkable thing is that the scholars have already suggested the usage of Energy Plus and IES Virtual Environment programs for these purposes [7]. However, two disadvantages have been revealed in the framework of this approach: interfaces of the above programs are complicated for unprepared users and, moreover, for the customers and potential buyers; besides, the programs do not provide for visualization of the obtained results, which decreases the demonstrativeness of conducted investigations.

The article [8] dwells upon real problems of the VR application in architecture, engineering, construction and facilities management (AEC/FM or Architecture, Engineering, Construction and Facility Management). The $\mathrm{VR}$ is used for solving various problems of engineering, construction and operation, including coordination of engineering $[9,10]$, project planning [11], instructing construction [12, 13], safety engineering [14], coordination of construction work [15], management of facilities under construction [16] and real property [17]. However, they emphasize the following remarks on converting BIM model into the VR by means of the game engine Unity 3D [8]. First of all, thus far it is impossible to synchronize the exchange of visual component of model between program for creating the BIM model Revit and the game engine Unity 3D in the real time mode. It sophisticates the working process and contemplates heavy consumption of time for implementation of the ready VR application. Secondly, in case of any export and import of models there is no chance for synchronization of changes of informational model in the real-time mode.

By now the scholars have introduced such a concept as the modeling of energy consumption of the building (Building Energy Modeling - BEM), in which framework the data is taken into account that influences the building energy demands: climatic zone, building orientation in the cardinal directions and wind rose diagram, facility geometry, design and equipment using energy [18]. The use of the BEM helps to reduce the construction cost by selecting the most suitable materials, equipment and determining optimal dimensions of the building, reduce the annual operating costs and, in general, provide comfortable environment for staying in the building.

The temperature of air in premises is distributed nonuniformly and depends on many factors: location of windows, doors, heat sources and ventilation system [19]. It is important to note that all these parameters bring about a change of heat comfort in the building. The heat comfort is also influenced by air temperature, average radiation temperature, air velocity and relative humidity. Besides, the psychological egocentric parameters can also influence the assessment of heat comfort [20]. Most frequently the researchers attempt to find some averaged value for assessing the heat comfort instead of allowing the future facility user selecting personally the parameters comfortable for itself.

From the mathematical point of view Boussinesq equations give the most precise description of the process of heat-and-mass transfer in gas taking into account convection [21]. The model includes Navier-Stokes equation, heat transfer equation and incompressibility condition. The main idea of approximation consists in a specific feature of accounting dependence of density on temperature:

$$
\begin{gathered}
\rho_{0}\left(\frac{\partial \stackrel{\mathrm{r}}{v}}{\partial t}+(\stackrel{\mathrm{r}}{v} \cdot \nabla) \stackrel{\mathrm{r}}{v}\right)=-\nabla p+\eta \Delta \stackrel{\mathrm{r}}{v}+\rho(T) \stackrel{\mathrm{r}}{g}, \\
\frac{\partial T}{\partial t}+\stackrel{\mathrm{r}}{v} \cdot \nabla T=\chi \Delta T, \\
\operatorname{div} \stackrel{\stackrel{1}{v}}{=}=0,
\end{gathered}
$$

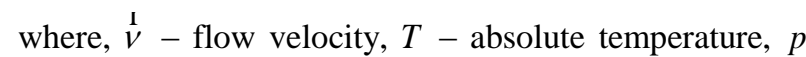
- pressure, $\eta$ - dynamic viscosity, $\chi$ - temperature conductivity coefficient, $\stackrel{\mathrm{I}}{g}$ - free-falling acceleration.

If this equation is solved by the Direct Numerical Simulation, (DNS), immense calculating capacities, a big 
volume of memory of calculating machines will be required [22]. In order to solve equation (1) in case of turbulent mode, it is necessary to have adequate networks with very low spacing. The time increment should be also very low. Moreover, a demand for calculation resources grows approximately in proportion to the cube from Reynolds number in the flow under consideration. There are different methods of approximation of equation solution (1), but they need to be separately studied in detail.

One of the important achievements in numerical mathematics is the development of economical finite difference methods for solving multidimensional equations in partial derivatives. Research [23] gives consideration to four basic methods of solving the difference scheme: the method of successive over-relaxation (SOR); the SOR method with optimization (SOR Ch); the block method of relaxation (SLOR); the alternating direction implicit method (ADI). The most productive is the alternating direction implicit method (ADI), which has been adopted conducting the research described in this work.

\section{METHODS}

The heat mode of premises, which determines the heat comfort of people, normal run of production processes, state and durability of building structures and its equipment, is the determinative one during operation of buildings. The distribution of air temperatures in a closed space is a complex physical process. A convective heat exchange appears in the course of interaction of air flows with the surfaces of enclosing structures, instruments of heating and cooling system. As a result a turbulent exchange of no isothermal air flows with the premises' main volume air emerges [24]. An important component of the complex process forming up the heat mode of the premises is the heat exchange at the surfaces. A demand for right choice of heating and cooling equipment in premises as well as the choice of construction materials helping to make the building more energy-efficient emerges in this regard.

A study of the formulated problem involves many disciplines, such as construction thermo physics, thermodynamics, heat-mass-exchange, numerical methods of solving differential equations. There are many studies and preliminary findings in every such sphere, though not all theoretical solutions have found the application thereof in the real life. Many preliminary studies of the $60-70$ s begin to be used in mathematic modeling of thermo physical processes at the beginning of the 21 century only, which is connected with distribution of heavy-duty personal computers, improvement of software thereof and development of visualization facilities

The heat transfer process itself has been taken as a basis of research in this work; therefore, a corresponding differential equation will be used [25]:

$$
\frac{D T}{t}=\frac{\square}{c} \frac{{ }^{2} T}{x^{2}}+\frac{{ }^{2} T}{y^{2}}+\frac{{ }^{2} T}{z^{2}} \square=a \square^{2} T .
$$

Here, $\lambda-$ heat transfer coefficient, $c_{\rho}-$ coefficient of specific heat per unit mass, $\rho$ - density, $a$ - temperature conductivity coefficient.
In order to find solution with specific initial conditions, it is necessary to meet the conditions of uniqueness. The uniqueness conditions for the limited space of the defined geometric shape with specified (known) physical properties are confined for setting the initial and boundary conditions. These conditions are referred to cumulatively as the boundary conditions [26]. In general case such conditions are described below for $3 \mathrm{D}$ area $\Omega$.

Initial conditions look as follows:

$$
T(0, x, y, z)=T_{0}(x, y, z), \text { where } x, y, z \in \Omega
$$

The boundary conditions set along the boundary $\partial \Omega$ describe the heat interaction with the environment and look as below with the permanent temperature at the boundary:

$$
T(t, x, y, z)=T_{1}(t, x, y, z), \text { where } x, y, z \in \Omega
$$

It is possible to use two fundamentally different approaches for the numerical solution of equations (4)-(6): variation method and finite difference method. The second variant will be used further in this work, since it is subject to programming to a greater degree.

ADI method has been applied for compiling an algorithm of solving equations described above (4)-(5). A solution along one of three directions $(x, y, z)$ is located at every "half step". Further, the found solutions help to find new $(n+1)$ solutions, etc in the limited quantity of iterations $(n=0 . .1000)$. Essentially, the quantity of iterations sets the time interval. As a result, a code in programming language $\mathrm{C}++$ has been written according to this algorithm.

The following parameters are necessary for the development of mathematic model of building energy efficiency:

- areas of all enclosing structures;

- coefficients of heat transfer of enclosing structures;

- data on temperature outside and inside of the building.

The first and the second one have been taken from the attributes of the BIM model. A user itself will select temperature inside of the building taking into account its own preferences regarding heat comfort. The temperature outside will be taken from SP 131.13330.2012 "Construction climatology" [27]. The data for Saint-Petersburg is used in this work (Table 1).

TABLE I. AVERAGE-MONTHLY AND AVERAGE-ANNUAL TEMPERATURE IN SAINT-PETERSBURG

\begin{tabular}{|c|c|c|c|c|c|c|c|c|c|c|c|c|c|}
\hline & I & II & III & IV & V & VI & VII & VIII & IX & X & XI & XII & Year \\
\hline $\begin{array}{c}\text { Saint- } \\
\text { Petersburg }\end{array}$ & -6.6 & -6.3 & -1.5 & 4.5 & 10.9 & 15.7 & 18.3 & 16.7 & 11.4 & 5.7 & 0.2 & -3.9 & 5.4 \\
\hline
\end{tabular}

With the knowledge of all these parameters, it is possible to find the heat losses through external enclosures by means of the following formula: 


$$
T_{i}=K_{i}\left(\tau-t_{\text {cp. } i}\right) F_{i},
$$

where, $K_{i}-$ coefficient of heat transfer from the enclosure inner surface to external medium, which temperature equals $t_{\mathrm{cp} . i}, F_{i}$ - area of enclosure surface, $\mathrm{M}^{2}$, $\tau$ - temperature inside of the building.

The air of premises coming in contact with heated or cooled surfaces gets heated or cooled. Besides, it receives or gives up heat in the process of heat exchange. The equation of air heat balance in the premises looks as follows:

$$
\sum T_{i} \pm Q_{\mathrm{B}}=0,
$$

where, $Q_{\mathrm{B}}$ - amount of convective heat, which is directly transferred through air of premises or taken from it [21].

The area of enclosing structures is determined automatically in the program, after that the necessary coefficients are taken from the attributes of BIM model and cumulative heat losses for a year will be found. A calculation of optimal quantity of alternative sources of energy entirely covering the expenditures for heating is included into the program mathematic model, for which purpose a simplex method is used: the quantity of energy sources is used as variables, while the minimized objective function is the cumulative cost thereof. The limitations are set by the equality between the cumulative average generated energy and all heat losses. The initial data for calculation and setting a task of optimization are presented in Tables 2 and 3, accordingly.

TABLE II. INITIAL DATA

\begin{tabular}{|c|c|c|c|}
\hline & $\begin{array}{c}\text { Quantity, } \\
\text { pcs }\end{array}$ & $\begin{array}{c}\text { Average } \\
\text { power, } \\
\mathbf{k W / y}\end{array}$ & $\begin{array}{c}\text { Cost, thous. } \\
\text { rub. }\end{array}$ \\
\hline Solar cell panels & $x$ & $Q_{x}$ & $S_{x}$ \\
\hline Wind turbines & $y$ & $Q_{y}$ & $S_{y}$ \\
\hline
\end{tabular}

TABLE III. SETTING OPTIMIZATION TASK

\begin{tabular}{|c|c|c|}
\hline Objective function & $x \cdot S_{x}+y \cdot S_{y}$ & $\rightarrow \min$ \\
\hline Limitation & $x \cdot Q_{x}+y \cdot Q_{y}$ & $\geq \sum T_{i}$, \\
\hline
\end{tabular}

The next task being considered is the issue of payback of using alternative energy sources. The cumulative cost of solar cell panels and wind turbines specified earlier is taken into account. The cost of expenditures for heating by electricity during a year without using the inherent generators (tariff for Leningrad region is $3.46 \mathrm{rub} / \mathrm{kW} \cdot \mathrm{h}$, including VAT) is calculated [28]. A period of generators payback without account of the growth of tariffs is calculated with the use of the acquired data according to the following formula:

$$
T=\frac{S}{3.46 \cdot Q}
$$

where, $S$ - cumulative cost of the used alternative energy sources, $Q$ - heat losses over a year.

\section{RESULTS}

The user can individually set the temperature inside of the building in the created interactive digital model. As a result, the program will automatically calculate the amount of heat losses and the alternative energy sources covering thereof as well as the period of payback of theses sources and output these to a screen (Fig. 1).

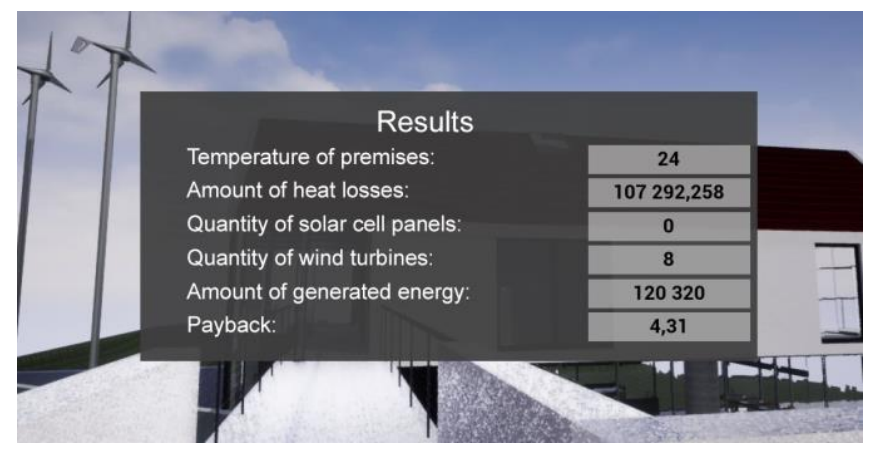

Fig. 1. Result of Program for Calculation of Building Energy Efficiency at Temperature of Premises of $24^{\circ} \mathrm{C}$.

There is also a possibility of changing temperature at the surface of heating appliances (warm floor and radiators) and see the result of distributing temperatures of air masses inside of the premises in the real-time mode. Figure 2 shows the display from the received application, where an indicator of average temperature in an apartment is highlighted in the upper left corner. While the color of a particle and a sphere is dependent on the temperature in this point. A gradient from blue to red shows a distribution of temperatures, where the bright blue color corresponds to $10{ }^{\circ} \mathrm{C}$, and bright red corresponds to $50^{\circ} \mathrm{C}$.

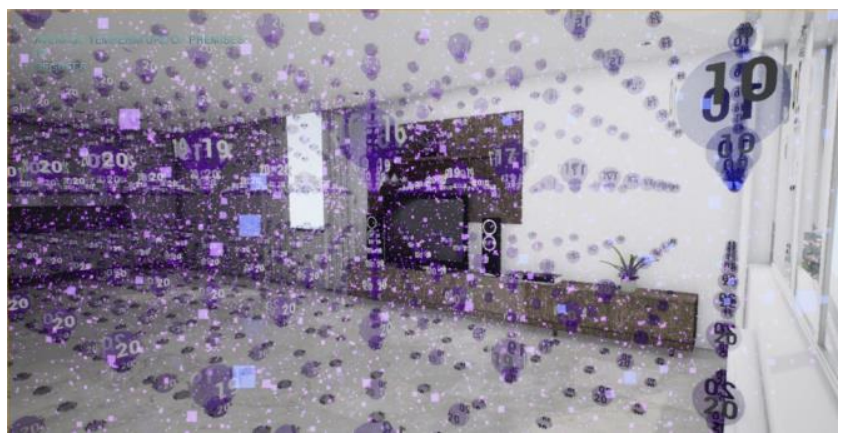

Fig. 2. Distribution of Temperature in Premises without Using Systems of Heating. T av. $=19^{\circ} \mathrm{C}$.

The image above demonstrates that absolutely any interference influences the heat comfort in the premises. So, an important point in the given calculation is that the maximum part of the external wall is a window with maximum temperature of $1{ }^{\circ} \mathrm{C}$. It has been decided for the obviousness of results to take specifically the difficult-toheat premises with big area of premises and windows, and two external walls. 
One more result of this program functioning is a "submergence" of an individual into completed construction facility, a change of the time of day was also implemented. With respect to photorealistic aspect the application is as good as such ranger-plug-in as V-Ray or Corona frequently used by architectural engineers and designers (Fig. 3).

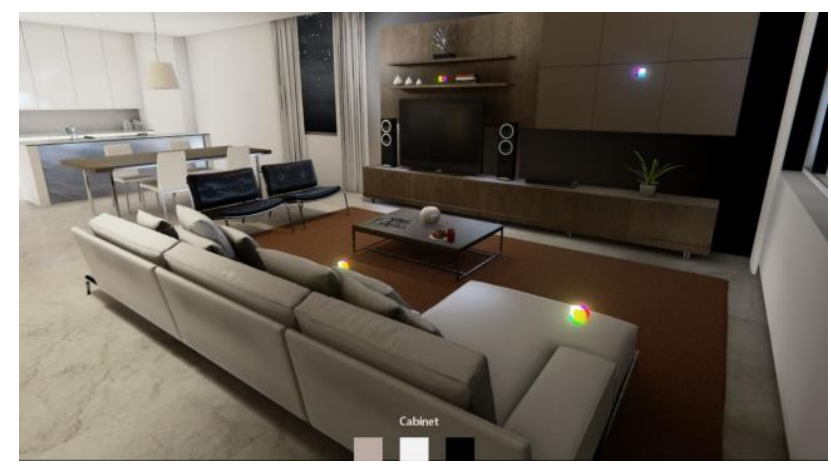

Fig. 3. Implementation of Change of Material and Lighting.

\section{DISCUSSION}

One can see that the use of the game engine such as Unreal Engine is much more efficient as the Unity 3D for solving the set task. Much time is spent during export of the BIM model created in Revit into the game engine Unity 3D for its conversion into the VR-project (from a couple of hours to a couple of days). All necessary informational model of the building is also lost during export, which implies additional expenditures of time for programming and manual input of data into design in the game engine. Such an export takes a couple of minutes in the Unreal Engine and, at that; the model attributes are not lost. It should be noted that the engine such as Unreal Engine is free for all development agencies, while the products created on its basis may be applied in the majority of operational systems and platforms.

One of the tasks of the project was to create the BIM model with a definite set of parameters. Subsequent to the results of comparative analysis, Autodesk Revit is a leader on the software market implementing the BIM concept [29]. The Autodesk Revit also provides interaction with the game engine Unreal Engine by means of the plug-in Datasmith.

Creating the information model of construction facility in the Autodesk Revit, it is important to assign the heat conductivity parameters to the building elements. No problems appear when dealing with walls and roof, since the heat conductivity coefficient can be changed in the material structure. However, when dealing the windows and stainedglass windows, this coefficient depends on selection of the limited set of analytical structures. Editing parameters for these structures, including the heat transfer coefficient too is not available to the users and is kept in the auxiliary file *.XML. In order to add the non-standard parameters, it is necessary to edit and address the mark-up of this file *.XML.

It has been decided initially to implement everything by means of the built-in graphical language of programming Blueprint in the course of developing the mathematic model in the game engine Unreal Engine [30]. This solution could simplify the process of data import to the facilities in the scene itself and could help much quicker to show the distribution of temperature comfort inside of the building. Though, since the Blueprint is intended for operation with the scene logic, but not for solving complex mathematic models, then $\mathrm{C}++$ class has been implemented owing to the built-in programming capability at the game engine in the Visual Studio, which helped to solve the 3D differential equation.

The interactive digital model obtained in this work may be useful for tenant builders and developers of the Russian Federation. Such an application can considerably increase a demand for the up-to-date "smart homes" and apartments as well as increase the buyers' interest to energy-efficient accommodation. The work results may be also efficient in scientific and educational spheres [31]. The VR means used in the construction sphere also help adequately solve many issues virtually. For instance, a buyer of construction facility can stay in another country, but comprehensively evaluate and reveal the subtleties of the future building without visiting the seller or the construction site, which can increase the attractiveness of facilities for investing by the foreign partners, as well as add to marketability in general. Moreover, the designers themselves can remotely solve the problems arising in the process of construction, while the personnel dealing with project implementation can study peculiarities of future construction project from inside.

For the moment there are many software complexes performing mathematic modeling of thermo physical processes (ANSYS, COMSOL, ELCUT). These programs use both the models described in equations (1)-(3), and more sophisticated too [32]. It should be noted that the results of calculating these programs on heat transfer get output only in the form of flats of space, diagrams and tables. Furthermore, these programs feature complex interface and require special skills, e.g., with "COMSOL Multiphysics", which analyzes, forecasts and optimizes the engineering solutions by means of multi-physical modeling. A distinctive feature of the developed digital model is a capability to output the results in the real-time mode, in 3D space and visually observe thereof due to use of the VR, which significantly expands the capabilities of using this application by the customers, users and would-be buyers.

\section{FINDINGS}

It is assumed that already at the stage of $20 \%$ of design solution availability $80 \%$ of processes accompanying building operation are determined [2]. The building of the BEM model on the basis of being-built BIM model is presently quite wide-spread, which makes it possible to select the most suitable materials and structures at the stage of engineering. Nevertheless, the above models can be developed and analyzed by professionals only, who possess special knowledge and skills. Moreover, there exist difficulties in correct export of data from BIM to BEM model at this stage of technologies development [2].

A joint use of the BIM and virtual reality particularized in this work will help to build an interactive digital model easy-to-understand even for the unprepared users that can be used in the marketing activity as well as for increasing the general public awareness of the energy-efficiency and its advantages.

The application of virtual-reality technologies in construction helps to clarify the parameters of decisions being adopted, significantly improve VDC. Besides, the 
rendering in real-time mode gives a chance to demonstrate all the design details before it is implemented.

An interactive digital model performs the heat-balance calculations and finds a necessary amount of energy for heating taking into account a coefficient of heat transfer of the enclosure structures taken from BIM model and average air temperature outside with due account of the climatic zone.

The digital model in the framework of the developed application makes it possible to assess the facility not built yet both from inside and from outside and does not require any special skills or knowledge of programs for 3D modeling. This software product can be also used by organizations specialized in selling and construction of private residential houses. The digital model helps to held presentations of the construction facilities for the would-be buyers at high level as well as open up opportunities for independent planning of the interior appearance and solving issues related to energyefficiency of the building.

One more variant of using the acquired digital model is a possibility of training future BIM experts. It is sufficient to that effect to add the interactive informational resources to the virtual environment, which will provide for joint training of the experts in the sphere of energy-efficiency calculations, engineering and construction. Such a method is sufficiently suitable for training experts territorially remote from each other and from the site of carrying out construction and installation works.

The results obtained in the work are not final: presently a method of finite elements is being incorporated, which will help to add the solution of Boussinesq equations, where the process of air masses motion will be taken into account. It is planned to improve the algorithm of solving the 3D management of heat conductivity in future due to use of such technologies as CUDA [33].

\section{REFERENCES}

[1] United Nations, " $68 \%$ of the world population projected to live in urban areas by 2050, says UN," 2018 , https://www.un.org/development/desa/en/news/population/2018revision-of-world-urbanization-prospects.html

[2] B. Lack and S. Butler, Bridging BIM and BEM: the path forward to more efficient building design and operations, 2019, pp. 14, https://download.schneiderelectric.com/files?p_enDocType $=$ White+Paper\&p_File_Name=998 20501257_WP-Bridging+BIM+and+BEM.pdf\&p_Doc_Ref=99820501257_WP

[3] B.A. Nikolaev, "The first active house," Pivot, No. 198, 2015, https://www.to-inform.ru/index.php/arkhiv/item/perviy-aktivniy-dom

[4] A. Vishnivetskaya and A. Mikhailova, "Employment of BIM technologies for residential quarters renovation: global experience and prospects of implementation in Russia," IOP Conf. Ser.: Mater. $\begin{array}{llll}\text { Sci. } & \text { Eng., } & \text { vol. } & 497,\end{array}$ https://iopscience.iop.org/article/10.1088/1757-899X/497/1/012020

[5] N.V. Pakhomova, K.K. Rikhter, V.M. Zhigalov and A.S. Malova, "Energy-efficiency management in the context of new climatic policy," Regional economics, vol. 13 (1), 2017, pp. 183-195.

[6] D. McNell, H. Allison, W. Black and M. Cukrow, "Building Information Modeling," InfoComm International, 2014, p. 26.

[7] C.-S. Cho, D. Chen and S. Woo, "Building Information Modeling (BIM)-Based Design of Energy Efficient Buildings," 28th International Symposium on Automation and Robotics in Construction, 2011, DOI: 10.22260/ISARC2011/0198

[8] J. Dua, Z. Zoua, Y. Shia and D. Zhaob, "Zero latency: Real-time synchronization of BIM data in virtual reality for collaborative decision-making," Automation in Construction, vol. 85, 2018, pp. 5164.

[9] J.I. Messner, S.C. Yerrapathruni, A.J. Baratta and V.E. Whisker, "Using virtual reality to improve construction engineering education," American Society for Engineering Education Annual Conference \& Exposition 2003 , https://www.researchgate.net/profile/Anthony_Baratta/publication/24 9864710_Using_Virtual_Reality_to_Improve_Construction_Engineer ing_Education/links/00b7d53a050f2ee407000000.pdf.

[10] J. Whyte, "Industrial applications of virtual reality in architecture and construction," Special issue Virtual Reality Technology in Architecture and Construction, vol. 3, 2003, pp. 43-50, http://itcon.org/paper/2003/4.

[11] J. Du, Y. Shi, C. Mei, J. Quarles and W. Yan, "Communication by Interaction: A Multiplayer VR Environment for Building Walkthrough," ASCE Construction Research Congress (CRC) 2016, ASCE, Puerto Rico, 2016, http://dx.doi.org/10.1061/9780784479827.227.

[12] H. Kaufmann, D. Schmalstieg and M. Wagner, "Construct3D: a virtual reality application for mathematics and geometry education," Education and Information Technologies, vol. 5(4), 2000, 263-276, http://dx.doi.org/10.1023/A:1012049406877.

[13] P.V. Rekapalli and J.C. Martinez, "Gaming perspective based visual interactive simulation for validation of simulated construction operations," International Workshop on Computing in Civil Engineering, 2007, http://dx.doi.org/10.1061/40937(261)53.

[14] R. Sacks, A. Perlman, R. Barak, "Construction safety training using immersive virtual reality", Construction Management and Economics, vol. 31(9), 2013, pp. http://dx.doi.org/10.1080/01446193.2013.828844.

[15] D. Bouchlaghem, H. Shang, J. Whyte and A. Ganah, "Visualisation in architecture, engineering and construction (AEC)," Automation in Construction, vol. 14(3), 2005, pp. 287-295, http://dx.doi.org/10.1016/j.autcon.2004.08.012.

[16] Kalyazina S., Lepekhin A. (2018) Implementing an energy harvesting technology within the concept of Smart city. MATEC Web of Conferences, Volume 193, 01030.

[17] S.E. Chen, "Quicktime VR: an image-based approach to virtual environment navigation," Proceedings of the 22nd Annual Conference on Computer Graphics and Interactive Techniques, ACM, 1995, pp. 29-38, http://dx.doi.org/10.1145/218380.218395.

[18] E. Franconi, K. Tupper, B. Herrschaft, C. Schiller and R. Hutchinson, "Building energy modeling for owners and managers: A guide to Specifying and Securing Services", Rocky Mountain institute, 2013, p. 30.

[19] Y.-W. Lim, "Building Information Modeling for Indoor Environmental Performance Analysis," American journal of environmental sciences, vol. 11(2), 2015, pp. 55-61.

[20] G. de Dear and R. Brager, "Developing an Adaptive Model of Thermal Comfort and Preference," ASHRAE Trans, vol. 104 (1), 1998, pp. 145-167.

[21] V. I. Bodrov, M. V. Bodrov, V. F. Bodrova and V. Yu. Kuzin. "Construction thermophysics," Nizhny Novgorod: Nizhny Novgorod State University of Architecture and Civil Engineering, 2015, 157 p.

[22] A.M. Molchanov, D.S. Yanysheva and A.A. Anikeyev, "Fundamentals of calculated heat exchange and hydrodynamics," Moscow : URSS, 2010, $150 \mathrm{p}$.

[23] Yu. N. Zgoda, “Comparing different methods of solving Poisson's equation," Collection of writings of the 69th All-Russia scientific and practical conference of students, postgraduate students and young scholars "Current construction problems", 2016, pp. 38-43.

[24] V. Bogoslovsky, "Construction thermophysics," Moscow: Vysshaya shkola, 1982, $157 \mathrm{p}$.

[25] M. A. Mikheyev and I. M. Mikheyeva, "Heat-transfer principles," Moscow: Energiya, 1977, 344 p.

[26] E. Kartashov, "Analytical methods in the theory of thermal conductivity of solid bodies," Moscow: Vysshaya shkola, 2001, 550 p.

[27] SP 131.13330.2012 Construction climatology. Updated edition of SNiPI 23-01-99* (with revisions Nos 1, 2), M.: FSUE Center of design deliverables for wide use, 2012, $113 \mathrm{p}$. 
[28] Tariffs for electric energy for Saint-Petersburg, https://www.pes.spb.ru/for_customers/electricity_tariffs/electricity_ta riffs_for_st_petersburg

[29] Google Trends, https://trends.google.ru

[30] T. Shannon, "Unreal Engine 4 for Design Visualization: Developing Stunning Interactive Visualizations, Animations and Renderings," Addison-Wesley Professional, 2017, p. 384.

[31] O.M. Shakshak and I.A. Evsikov, "Use of virtual reality (VR) as the means of architectural vizualization," Architechton: proceedings of HEIs, No. 4(64), 2018, pp. 352-360.

[32] M. A. Denisov, "Mathematical modeling of thermophysical processes. ANSYS and CAE-designing," Ekat: Ural Federal University, 2011, $150 \mathrm{p}$.

[33] A. Berillo, "Nvidia CUDA non-graphical calculations in graphical peocessors," iXBT Brand, 2018, https://www.ixbt.com/video3/cuda1.shtml 